\title{
Evidência de que o fungo Rhizoctonia solani AG-1 IA adaptado à Urochloa na Colômbia mantém ampla gama de hospedeiros incluindo o milho
}

\author{
Nadia Maria Poloni ${ }^{1}$, Lina Maria Ramos Molina ${ }^{2}$, Edisson Chavarro Mesa ${ }^{2,3}$ Izabela Lopes Garcia ${ }^{1}$, \\ Paulo Cezar Ceresini ${ }^{1}$
}

\begin{abstract}
${ }^{1}$ UNESP (Universidade Estadual Paulista), Campus de Ilha Solteira, SP, Brasil; ${ }^{2}$ UNESP, Campus de Jaboticabal, SP, Brasil; ${ }^{3}$ UNINCCA(Universidad INCA de Colombia), Bogotá, Colômbia

Autor para correspondência: Paulo Cezar Ceresini (paulo.ceresini@bio.feis.unesp.br)

Data de chegada: 20/04/2015. Aceito para publicação em: 17/03/2016.
\end{abstract}

$10.1590 / 0100-5405 / 2176$

\section{RESUMO}

Poloni, N.M.; Ramos Molina, L.M.; Chavarro Mesa, E.; Garcia, I.L.; Ceresini, P.C. Evidência de que o fungo Rhizoctonia solani AG-1 IA adaptado à Urochloa na Colômbia mantém ampla gama de hospedeiros incluindo o milho. Summa Phytopathologica, v.42, n.3, p.228-232, 2016.

O fungo Rhizoctonia solani grupo de anastomose AG-1 IA emergiu como patógeno importante associado à queima foliar, podridão do coleto e morte de pastagens do gênero Urochloa (braquiária) na América do Sul. Neste estudo objetivou-se determinar se a adaptação de $R$. solani AG-1 IA à Urochloa spp. na Colômbia promoveu diferenças fenotípicas de agressividade a hospedeiros distintos. Testou-se a hipótese de que as populações do patógeno adaptadas à Urochloa não são hospedeiro-especializadas e, desta forma, não estão geneticamente isoladas, mantendo assim ampla gama de hospedeiros, incluindo as fabáceas feijão caupi e soja. Determinou-se, também, se dois grupos de isolados obtidos de populações de $R$. solani
AG-1 IA amostradas de Urochloa na Colômbia tinham potencial adaptativo para emergir como patógeno do milho. Além do nível de agressividade da doença em diferentes hospedeiros, determinou-se os componentes de evolutibilidade como o coeficiente de variância genotípica $\left(I_{G}\right)$, de variância ambiental $\left(I_{E}\right)$ e a herdabilidade $\left(h^{2}\right)$. Concluiu-se que: i) A adaptação de $R$. solani AG-1 IA à Urochloa spp. não promoveu diferenças fenotípicas de agressividade em hospedeiros distintos e, desta forma, o patógeno mantêm ampla gama de hospedeiros; ii) A população de R. solani AG-1 IA de Urochloa híbrido Mulato da Colômbia tem potencial adaptativo para emergir como patógeno do milho.

Palavras-chave: fitopatógenos emergentes na agricultura, adaptabilidade patogênica, divergência genética, queima da braquiária, doenças de forrageiras

\section{ABSTRACT}

Poloni, N.M.; Ramos Molina, L.M.; Chavarro Mesa, E.; Garcia, I.L.; Ceresini, P.C. Evidence that the fungus Rhizoctonia solani AG-1 IA adapted to Urochloa in Colombia keeps a broad host range including maize. Summa Phytopathologica, v.42, n.3, p.228-232, 2016.

The fungus Rhizoctonia solani anastomosis group AG-1 IA has emerged as an important pathogen associated with foliar blight, collar rot and death of Urochloa (Brachiaria) forage pastures in South America. This study aimed to determine whether the adaptation of $R$. solani AG-1 IA to Urochloa spp. in Colombia promoted phenotypic differences in aggressiveness to distinct hosts. Our hypothesis was that the pathogen populations adapted to Urochloa spp. are not host-specialized and hence are not genetically isolated, thereby maintaining a broad host range, including the fabaceous plants cowpea and soybeans. We also determined whether two groups of isolates from populations of $R$. solani
AG-1 IA sampled from Urochloa in Colombia have adaptive potential to emerge as maize pathogens. Besides the levels of disease severity in different hosts, we also determined the components of evolvability, such as the coefficient of genotypic variance $\left(I_{G}\right)$, the environmental variance $\left(I_{E}\right)$ and the heritability $\left(h^{2}\right)$. We concluded that: i) The adaptation of $R$. solani AG-1 IA to Urochloa spp. did not cause any phenotypic differences in aggressiveness to distinct hosts and therefore the pathogen maintains a broad host range. ii) The population of R. solani AG-1 IA from Urochloa hybrid Mulato in Colombia has adaptive potential to emerge as a maize pathogen.

Keywords: emerging pathogens in agriculture, pathogenic adaptability, genetic divergence, Urochloa foliar blight, forage diseases

Nos anos 90, o fungo Rhizoctonia solani Kuhn grupo de anastomose 1 IA (AG-1 IA) emergiu como patógeno importante associado à queima foliar, podridão do coleto e morte de pastagens do gênero Urochloa na América do Sul $(8 ; 18)$. Os primeiros relatos dessa doença ocorreram na Colômbia, em áreas onde o cultivo de arroz (um hospedeiro altamente suscetível ao fungo $(15 ; 19)$ foi substituído pelo cultivo de pastagens do gênero Urochloa spp. (capim braquiária), em resposta à crescente demanda por pecuária extensiva (6; 25). A braquiária é uma forrageira muito importante na América Latina tropical, atingindo, somente no Brasil, mais de 160 milhões de hectares de cultivo (17). Em pastagens no Brasil, o patógeno foi relatado atacando especificamente $U$. brizantha cv. Marandu nos estados do Acre, Maranhão, norte do Mato Grosso,
Rondônia, sul do Pará e Tocantins, todos na região Amazônica $(11 ; 26)$.

Observações recentes sobre a biologia de populações de $R$. solani AG-1 IA, sugerem que este patógeno tem um alto potencial evolutivo para emergir como fitopatógeno em novos hospedeiros por apresentar sistema reprodutivo misto (que inclui a reprodução sexuada e a dispersão de clones adaptados), alto fluxo gênico e tamanho populacional e diversidade genética elevados $(3 ; 6 ; 7 ; 14 ; 22)$.

Evidências genético-populacionais obtidas na última década indicaram que a emergência de populações especializadas de $R$. solani AG-1 IA em novos hospedeiros ocorreu via troca, do arroz para o milho (14), ou salto de hospedeiros, do arroz para a soja (2). A troca de hospedeiro, devido à sobreposição (ou conectividade) de cultivos 
em áreas de cultivo de arroz foi, também, apontada como o principal mecanismo para a emergência da queima da braquiária na Colômbia (6).

A magnitude dos cultivos de braquiária na América do Sul mantendo conectividade espacial e temporal com outras culturas de importância econômica (o milho, por exemplo) aumenta a dinâmica de populações do patógeno entre cultivos e poderia levar populações de $R$. solani AG-1 IA adaptadas a pastagens a expandir sua gama de hospedeiros (4).

Há cerca de 25 anos, $R$. solani AG-1 IA emergiu causando a mancha bandeada do milho na Venezuela em áreas tradicionalmente usadas na produção de arroz $(5 ; 14 ; 23)$. A mancha bandeada do milho adquiriu, então, elevada importância na Venezuela devido à ineficácia das medidas para o manejo da doença como a aplicação de fungicidas e a rotação de culturas. A rotação de culturas é particularmente difícil considerando que R. solani AG-1 IA pode atacar tanto outras poáceas quanto fabáceas (5). Há variabilidade genética, entre genótipos de milho, para resistência à mancha bandeada. Entretanto, ainda não há disponibilidade de materiais comerciais de milho resistentes a $R$. solani AG-1 IA (23).

Com exceção da Venezuela, ainda não há relatos sobre a emergência da mancha bandeada do milho em outros agroecossistemas sul-americanos. Entretanto, é plausível a hipótese da emergência de $R$. solaniAG-1 IA como patógeno do milho tanto Brasil quanto na Colômbia, se o cultivo de milho expandir-se para áreas adjacentes ou antes cultivadas com hospedeiros suscetíveis ao patógeno, tais como o arroz, o feijão-caupi, a soja, e principalmente, a braquiária $(9 ; 13 ; 20 ; 25)$.

Sob essa perspectiva, os objetivos deste estudo foram: i) determinar se a adaptação de $R$. solani AG-1 IA à Urochloa spp. promoveu diferenças fenotípicas de agressividade a hospedeiros distintos. A hipótese é de que "as populações do patógeno adaptadas à Urochloa spp. não são hospedeiro-especializadas e, desta forma, não estão geneticamente isoladas, mantendo assim ampla gama de hospedeiros" ii) determinar se duas populações de $R$. solani AG-1 IA da Urochloa obtidas da Colômbia tem potencial adaptativo para emergir como patógeno do milho.

\section{MATERIAL E MÉTODOS}

Isolados de $R$. solani AG-1 IA foram coletados em 2011 de áreas de cultivo de $U$. brizantha cv. Toledo e de Urochloa híbrido Mulato no estado de Meta, na Colômbia (25). Os isolados foram genotipados usando nove loci microssatélites. De cada população, foram selecionados, ao acaso, doze isolados geneticamente distintos. Os isolados originais do patógeno foram conservados sob a forma de escleródios e micélio em grãos colonizados de arroz parboilizado mantidos em criotubos contendo sílica gel, a $-20{ }^{\circ} \mathrm{C}$. Cada isolado foi transferido e propagado em placas de Petri contendo $15 \mathrm{~mL}$ de meio BDA (batata-dextrose-ágar, KASVI, Curitiba, PR, Brasil). Para preparo de inóculo, grãos de arroz parboilizado umedecidos com uma solução de cloranfenicol e estreptomicina a $50 \mu \mathrm{g} . \mathrm{mL}^{-1}$, foram previamente autoclavados a $120^{\circ} \mathrm{C}$ por 30 minutos e então distribuídos em BDA contendo culturas puras de Rhizoctonia em crescimento por três dias. Após dois dias de incubação a $25^{\circ} \mathrm{C}$, grãos de arroz colonizados pelo fungo foram usados como inóculo. Grãos de arroz não colonizados, porém mantidos sob as mesmas condições, foram usados para inocular os controles.

Os experimentos de patogenicidade cruzada foram estabelecidos, conduzidos e avaliados de forma similar a estudos anteriores $(2 ; 14)$, descritos com mais detalhes a seguir. As plantas de feijão-caupi cv. IT86D-719, soja cv. BRS Valiosa e milho cv. Flintisa foram semeadas em copos descartáveis de $180 \mathrm{~mL}$ contendo, como substrato, vermiculita expandida de textura média e mantidos em casa de vegetação. Após a semeadura foi realizada adubação com solução de macro e micronutrientes. Foram conduzidos três experimentos distintos, um para cada hospedeiro. A inoculação das plantas de feijão-caupi e de soja foi efetuada após 13 ou 17 dias da semeadura, respectivamente, transferindo-se um grão de arroz colonizado por $R$. solani AG-1 IA para a região do pecíolo da primeira folha trifoliada, o qual foi mantido dentro de um pequeno cone de papel sulfite usado para dar suporte ao grão de arroz. Já a inoculação do milho foi realizada 18 dias após a semeadura, transferindo-se os grãos de arroz colonizados diretamente para a região da bainha da primeira folha verdadeira. Os copos contendo plantas inoculadas foram transferidos para bandejas e embalados dentro de sacos plásticos transparentes para manter atmosfera de alta umidade, e incubados a $25^{\circ} \mathrm{C}$, sob luz fluorescente contínua e fotoperíodo de 12 $\mathrm{h}$, até a avaliação.

A severidade da doença foi avaliada quatro (para feijão-caupi e soja) ou três dias após a inoculação (para milho), fotografando-se pelo menos uma folha infectada por planta. O nível de severidade da doença foi determinado com base na área foliar doente das folhas usando o software para análise de imagens digitais ASSESS da APS (American Phytopathological Society). A análise de variância foi efetuada usando o pacote de software estatístico SAS (versão 9.1 da SAS System for Windows; SAS Institute, Cary, Carolina do Norte, EUA). Nesta etapa do estudo foi determinado o efeito dos dois grupos de isolados do patógeno [de U. brizantha cv. Toledo (BBT) ou de Urochloa híbrido Mulato (BHM)] sobre a agressividade aos três hospedeiros distintos. As médias de agressividade dos grupos de isolados do fungo aos hospedeiros foram comparadas por contrastes de médias. Os experimentos foram delineados de forma inteiramente casualizada, com cinco repetições. Foram conduzidas duas réplicas dos experimentos. Como a interação tratamentos vs. experimentos foi não significativa, optou-se por utilizar os dados de um dos experimentos para representar os fenômenos aqui descritos.

Determinou-se, também, os componentes de evolutibilidade (isto é, uma medida do potencial adaptativo) do fungo para adaptar-se ao feijão caupi, à soja e ao milho. Para análise dos efeitos das populações de origem dos isolados de $R$. solani AG-1 IA da braquiária (BBT e BHM) sobre os componentes de evolutibilidade do patógeno, a variância explicada pelo fator isolados dentro de cada população foi interpretada como variância genética $\left(\mathrm{V}_{G}\right)$ e o erro experimental foi considerado como variância ambiental $\left(\mathrm{V}_{E}\right)$. A variância fenotípica foi calculada como $\mathrm{V}_{P}=\mathrm{V}_{G}+\mathrm{V}_{E}$. Os componentes de variância foram determinados por procedimento estatístico implementado no programa R. As variâncias obtidas foram padronizadas pelo quadrado da média da agressividade dos genótipos (ou isolados) do patógeno dentro de cada população $\left(m^{2}, i=1 \ldots n\right.$ genótipos), onde: $\mathrm{V}_{G} / \mathrm{m}_{i}{ }_{i}=1_{G i} ; \mathrm{V}_{E} /$ $\mathrm{m}^{2}{ }_{\mathrm{i}}=1_{E i} ; \mathrm{e} \mathrm{V}_{P} / \mathrm{m}^{2}{ }_{i}=1_{P}$, que são os coeficientes de variação para as variâncias genética $\left(I_{G i}\right)$, ambiental $\left(I_{E i}\right)$ e fenotípica $\left(I_{P i}\right)$, sendo então consideradas medidas de evolutibilidade ou de resposta à seleção (16). A herdabilidade média para o caráter agressividade do patógeno foi calculada como a razão entre a variância genotípica $\left(I_{G}\right)$ e a variância fenotípica $\left(I_{P}\right)$, ambas padronizadas. O intervalo de confiança a $95 \%$ para as estimativas de herdabilidade foram calculados por meio de análise de bootstrap ordinário ou não-paramétrico $(10 ; 12)$ baseada em 999 reamostragens de dados originais, onde em cada reamostragem obteve-se os componentes de variâncias e as respectivas herdabilidades como descrito anteriormente. O bootstrap foi implementado no ambiente R (24) onde utilizou-se os pacotes da distribuição base e o pacote "lme4" (1) para obter os componentes de variância do modelo misto considerado. 


\section{RESULTADOS E DISCUSSÃO}

O estudo indicou que os dois grupos de isolados de $R$. solani $\mathrm{AG}-1$ IA de Urochloa (BBTou BHM) obtidos na Colômbia foram altamente agressivos ao feijão-caupi, à soja e ao milho (Figura 1, Tabela1). Os

Tabela1. Teste de patogenicidade cruzada de Rhizoctonia solani AG-1 IA de Urochloa dos Llanos Colombianos ao feijão-caupi, à soja e ao milho.

\begin{tabular}{|c|c|c|c|}
\hline \multirow[t]{2}{*}{$\begin{array}{l}\text { Hospedeiro de origem } \\
\text { e grupo de isolados }\end{array}$} & \multicolumn{3}{|c|}{$\begin{array}{l}\text { Percentagem média de área foliar } \\
\text { infectada }\end{array}$} \\
\hline & $\begin{array}{c}\text { Feijão caupi } \\
\text { cv. IT86D-719 }\end{array}$ & $\begin{array}{c}\text { Soja cv. BRS } \\
\text { Valiosa }\end{array}$ & $\begin{array}{l}\text { Milho } \\
\text { Flintisa }\end{array}$ \\
\hline \multicolumn{4}{|c|}{ Urochloa brizantha cv. Toledo (BBT) } \\
\hline BBT1-A1 & 63,78 & 80,14 & 62,95 \\
\hline BBT1-A2 & 36,36 & 93,77 & 63,78 \\
\hline BBT1-A3 & 53,85 & 76,53 & 66,60 \\
\hline BBT1-A6 & 37,11 & 88,75 & 42,85 \\
\hline BBT1-D25 & 34,79 & 88,00 & 59,47 \\
\hline BBT1-E27 & 73,73 & 96,48 & 68,93 \\
\hline BBT2-A1 & 25,37 & 73,96 & 58,77 \\
\hline BBT2-A4 & 50,24 & 76,94 & 64,46 \\
\hline BBT2-A5 & 57,59 & 89,72 & 73,49 \\
\hline BBT2-B10 & 35,01 & 81,91 & 61,87 \\
\hline ВBT2-B16 & 53,53 & 76,33 & 84,38 \\
\hline BBT2-C24 & 43,25 & 98,33 & 79,28 \\
\hline $\mathrm{N}=12$ & 47,05 & 85,07 & 65,57 \\
\hline \multicolumn{4}{|l|}{$\begin{array}{l}\text { Urochloa hibrido Mulato } \\
\qquad \text { (BHM) }\end{array}$} \\
\hline BHM3-A1 & 61,06 & 81,44 & 70,80 \\
\hline BHM3-A10 & 35,11 & 79,76 & 79,35 \\
\hline BHM3-A5 & 26,20 & 75,01 & 16,80 \\
\hline BHM3-B11 & 51,98 & 90,98 & 70,13 \\
\hline BHM3-B13 & 39,21 & 93,80 & 91,57 \\
\hline BHM3-C28 & 79,33 & 99,81 & 67,40 \\
\hline BHM4-A10 & 48,42 & 86,60 & 52,53 \\
\hline BHM4-A4 & 65,78 & 82,36 & 74,07 \\
\hline BHM4-A5 & 77,53 & 92,83 & 65,34 \\
\hline BHM4-A6 & 54,86 & 90,99 & 41,92 \\
\hline BHM4-B19 & 43,35 & 99,40 & 54,25 \\
\hline BHM4-D36 & 66,14 & 59,74 & 84,46 \\
\hline $\mathrm{N}=12$ & 54,08 & 86,06 & 64,05 \\
\hline \multicolumn{4}{|l|}{ Todos os isolados } \\
\hline $\mathrm{N}=24$ & 50,57 & 85,57 & 64,81 \\
\hline Testemunha não inoculada & 0,00 & 0,00 & 0,00 \\
\hline \multirow[t]{3}{*}{$\begin{array}{l}\text { Contraste entre } \\
\text { grupos de } \\
\text { isolados }\end{array}$} & $-84,35$ & $-11,87$ & 18,21 \\
\hline & 1,91 & 0,10 & 0,11 \\
\hline & 0,17 & 0,75 & 0,73 \\
\hline
\end{tabular}

valores médios de agressividade foram 50,6, 85,6 e 64,8\% de área foliar infectada, para feijão-caupi, soja e milho respectivamente. Entretanto, não houve diferença significativa entre os grupos de isolados BBT e BHM ( $F$ contrastes de médias não significativos).

Soja e feijão-caupi já foram relatados como hospedeiros de $R$. solani AG-1 IA, especialmente no Brasil $(13 ; 20 ; 21)$. No agroecossistema sulamericano o milho só havia sido descrito como hospedeiro do patógeno na Venezuela (23). Os sintomas observados em milho inoculado com $R$. solani AG-1 IA de Urochloa da Colômbia assemelharam-se aos descritos por Perdomo e colaboradores (23).

Com relação à adaptabilidade de $R$. solani AG-1 IA de Urochloa da Colômbia a hospedeiros diferentes, estimada com base em medidas de evolutibilidade, observou-se que a origem dos grupos de isolados (BBT ou BHM) não influenciou a variância genotípica $\left(I_{G}\right)$ ou ambiental $\left(I_{E}\right)$ associada à agressividade do patógeno ao feijão-caupi e à soja, uma vez que tanto os valores de $I_{G}$ quanto os de $I_{E}$ não diferiram significativante (Figura 2). No geral observou-se também que, nos dois grupos de isolados, a variância ambiental $\left(I_{E}\right)$ para agressividade do patógeno foi significativamente maior que a variância genética $\left(I_{G}\right)$, quando se inoculou o feijão caupi e a soja. Isto resultou em valores relativamente baixos de herdabilidade (variando entre 0,19 a 0,38 ), refletindo, basicamente, o efeito da variância ambiental interferindo de forma distinta na expressão gênica de genótipos do patógeno. Ou seja, a variação na agressividade dos isolados de $R$. solani AG-1 IA das duas populações testadas dependeu basicamente das condições do ambiente (27).

Já em milho, a contribuição relativa da variância genética em relação à ambiental para agressividade foi maior no grupo BHM que no BBT, resultando em maior herdabilidade para este caráter $\left(h^{2}=0,62\right)$. Maior herdabilidade indica que a variação fenotípica na agressividade dos isolados do grupo BHM é um excelente previsor do potencial adaptativo de $R$. solani AG-1 IA para emergir como patógeno do milho, pois indica maior contribuição de componentes genéticos sobre o fenótipo.

Pela semelhança entre os patossistemas tropicais sul-americanos, é provável que processo semelhante ao descrito na Venezuela venha ocorrer também com populações colombianas, e talvez com as brasileiras, do patógeno. Até o momento da conclusão desta pesquisa, ainda não dispúnhamos de populações brasileiras de $R$. solaniAG-1 IA que infectam Urochloa. Entretanto, amostragens recentes conduzidas por nosso grupo de pesquisa foram realizadas na Amazônia brasileira e populações do patógeno estão sendo caracterizadas geneticamente $\mathrm{e}$ fenotipicamente, para estendermos o escopo deste estudo (6).

A adaptação de $R$. solani AG-1 IA à Urochloa spp. não promoveu diferenças fenotípicas de agressividade a hospedeiros distintos como feijão caupi, soja e milho. Os dois grupos distintos de isolados não apresentaram indícios de especialização mantendo, assim, ampla gama de hospedeiros.

O grupo de isolados obtido da população $\mathrm{BHM}$ de $R$. solani AG-1 IA de Urochloa híbrido Mulato na Colômbia tem potencial adaptativo para emergir como patógeno do milho naquele país.

\section{AGRADECIMENTOS}

Este estudo foi financiado por auxílio à pesquisa concedido pela Fundação de Amparo à Pesquisa do Estado de São Paulo - FAPESP / Programa Biota a P. C. Ceresini (FAPESP 2011/50150-3), por bolsa de produtividade à pesquisa (Pq-2 307361/2012-8 e 307295/20150) e auxílio (CNPq 485244/2012-8) do Conselho Nacional de Desenvolvimento Científico e Tecnológico (CNPq) a P. C. Ceresini. L. M. Ramos Molina recebeu bolsa de doutorado do CNPq - DR 

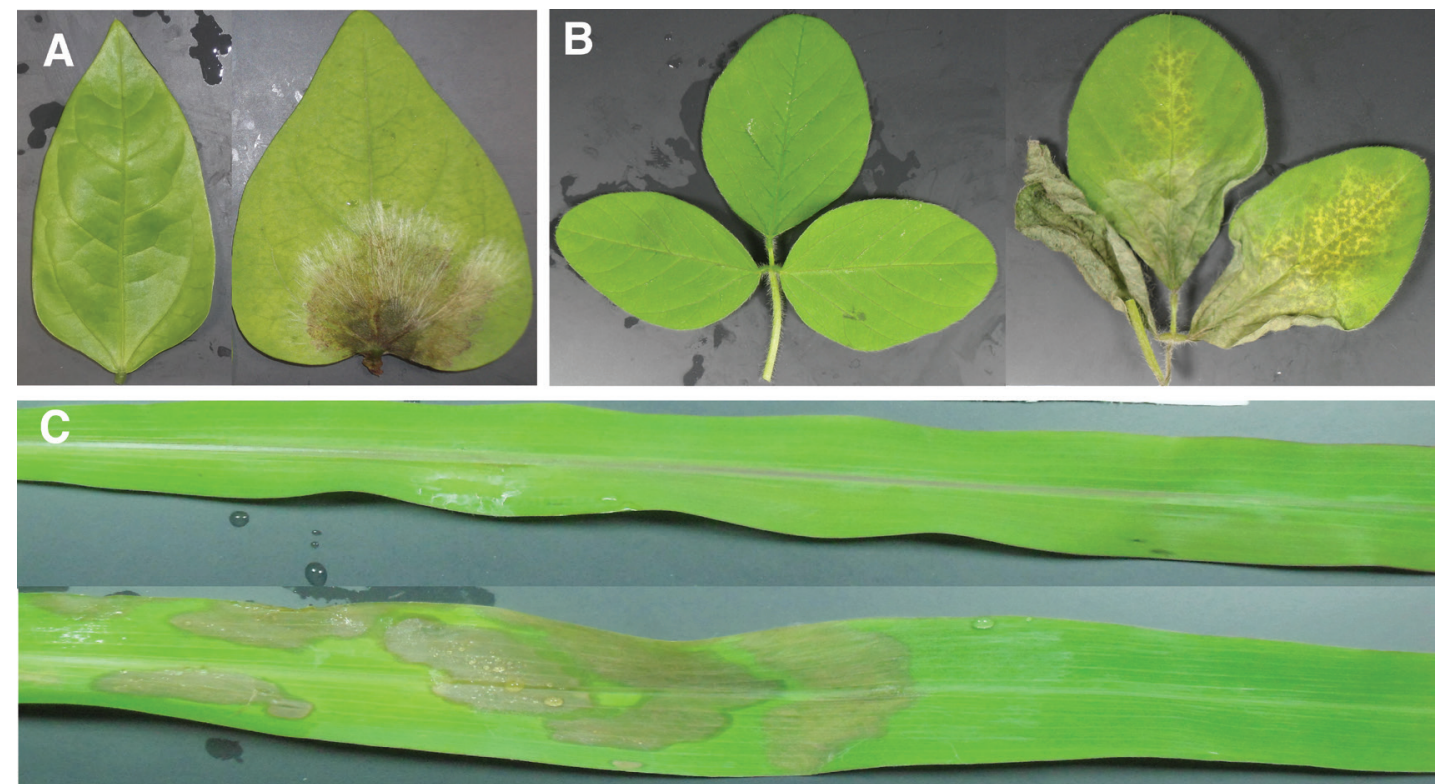

Figura 1. Sintomas de mela do feijão caupi (A) e da soja (B) e de mancha bandeada do milho (C) em folhas de plantas inoculadas com Rhizoctonia solani AG-1 IA de Urochloa. Folhas sem sintomas se referem aos controles não inoculados.
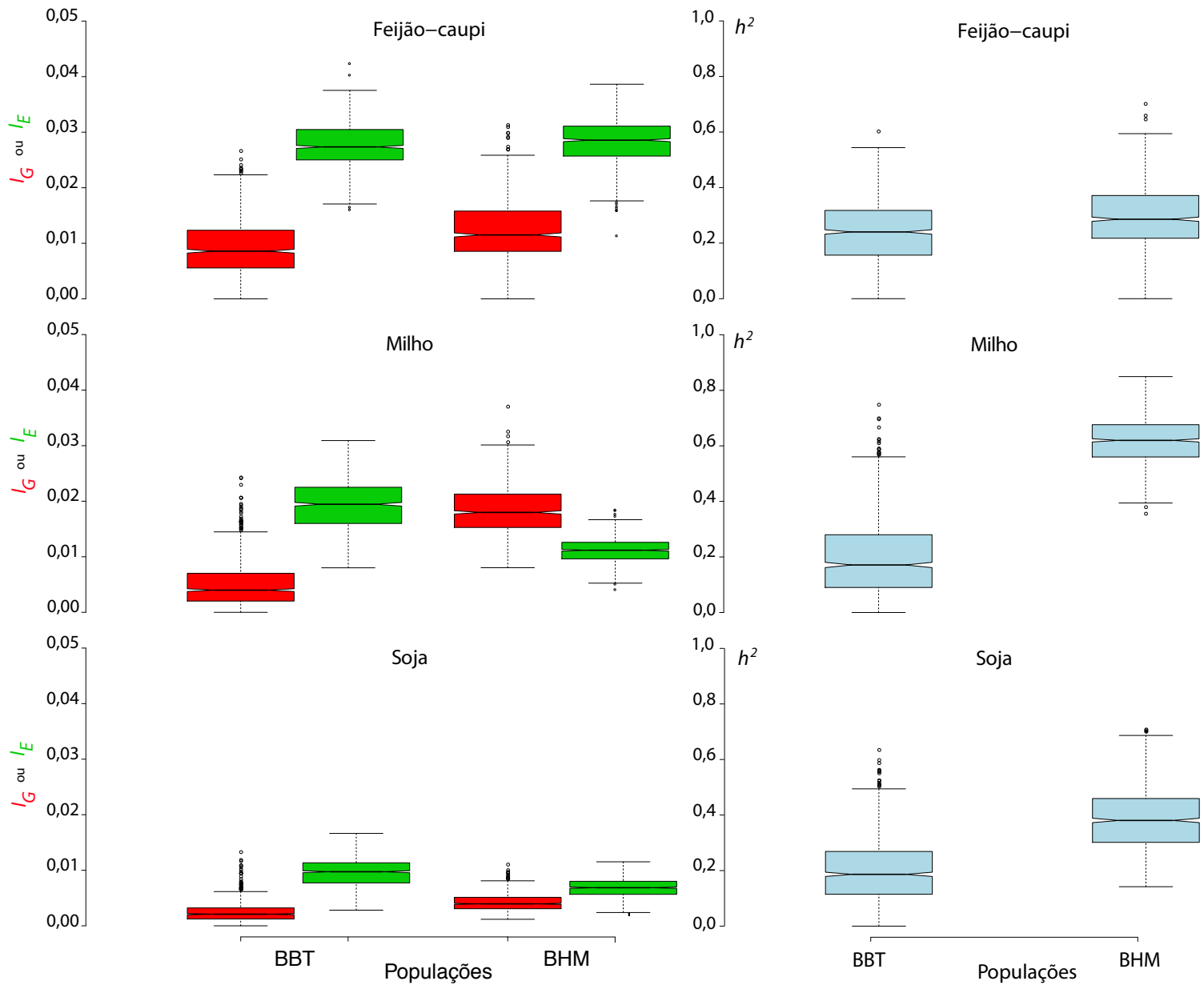

Feijão-caupi

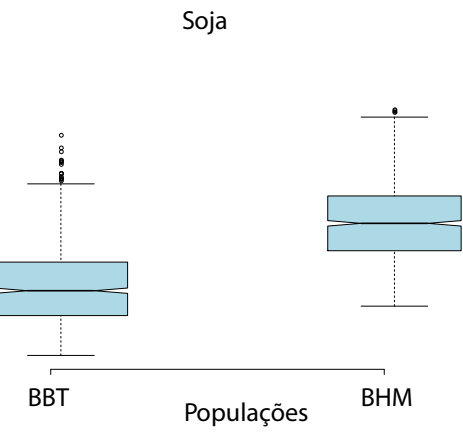

Figura 2. Componentes de evolutibilidade $\left(I_{E}=\right.$ variância ambiental, $I_{G}=$ variância genética, ambas padronizadas $)$ e herdabilidade $\left(h^{2}\right)$ para agressividade ao feijão-caupi, ao milho e à soja, como resposta aos efeitos de dois grupos de isolados de Rhizoctonia solani AG-1 IA de Urochloa (BBT e BHM) na Colômbia.*

* Os diagramas de caixas (boxplots) contém a linha da mediana aproximadamente em seu centro e 50\% dos dados (entre os quartís 25 e $75 \%$ ) gerados por bootstrap considerando 999 re-amostragens. As barras verticais indicam os valores máximos e mínimos observados e os círculos os valores atípicos. O entalhe marca o intervalo de confiança de $95 \%$ para as medianas. 
(140564/2009-8), E. Chavarro Mesa recebeu bolsa de doutorado da FAPESP (2011/23050-8) e N. M. Poloni recebeu bolsa de mestrado da CAPES pelo programa de pós-graduação em Agronomia - UNESP Campus de Ilha Solteira. I.L. Garcia recebeu bolsa de IC do CNPq (CNPq-IC 117888/2013-3). Agradecemos a A. Y. Perez Barragan (CNPq-AT 376421/2012-6), M. M. Negrisoli (CNPq-IC 163835/20128) e S. N. Campos (CNPq-AT 370186/2015-0) pelo apoio técnico nessa pesquisa.

\section{REFERÊNCIAS}

1. Bates, D.; Maechler, M. lme4: Linear mixed-effects models using S4 classes. R package version 0.999375-34. 2010. Disponível em: <http://CRAN.R-project.org/package $=1 \mathrm{me} 4>$. Acesso em: $01 \mathrm{dec} .2014$.

2. Bernardes de Assis, J.; Peyer, P.; Rush, M. C.; Zala, M.; McDonald, B. A.; Ceresini, P. C. Divergence between sympatric rice- and soybean-infecting populations of Rhizoctonia solani anastomosis group-1 IA. Phytopathology, v. 98, n. 12, p. 1326-1333, 2008.

3. Bernardes de Assis, J.; Storari, M.; Zala, M.; Wang, W.; Jiang, D.; Shidong, L.; Jin, M.; McDonald, B. A.; Ceresini, P. C. Genetic structure of populations of the rice-infecting pathogen Rhizoctonia solani AG-1 IA from China. Phytopathology, v. 99, n. 9, p. 1090-1099, 2009.

4. Burdon, J. J.; Thrall, P. H. Pathogen evolution across the agro-ecological interface: implications for disease management. Evolutionary Applications, v. 1, n. 1, p. 57-65, 2008.

5. Cardona, R.; Rodríguez, H.; Nass, H. Mancha bandeada en maíz causada por Rhizoctonia solani en el estado Portuguesa, Venezuela. Fitopatologia Venezolana, v. 12, n. 2, p. 32-33, 1999

6. Chavarro Mesa, E.; Ceresini, P. C.; Ramos Molina, L. M.; Pereira, D. A. S.; Schurt, D. A.; Vieira, J. R.; Poloni, N. M.; Mcdonald, B. A. The Urochloa foliar blight and collar rot pathogen Rhizoctonia solani AG-1 IA emerged in South America via a host shift from rice. Phytopathology, v. 105, n. 11, p. 1475-1486, 2015.

7. Ciampi, M. B.; Meyer, M. C.; Costa, M. J. N.; Zala, M.; McDonald, B. A.; Ceresini, P. C. Genetic structure of populations of Rhizoctonia solani anastomosis group-1 IA from soybean in Brazil. Phytopathology, v. 98, n. 8, p. 932-941, 2008.

8. CIAT. Annual Report, Tropical Forages Program. Palmira: CIAT - Centro Internacional de Agricultura Tropical, 1993. Document number 166.

9. Costa-Souza, E.; Kuramae, E. E.; Nakatani, A. K.; Basseto, M. A.; Prabhu, A. S.; Ceresini, P. C. Caracterização citomorfológica, cultural, molecular e patogênica de Rhizoctonia solani Kühn associado ao arroz em Tocantins, Brasil. Summa Phytopathologica, v. 33 n. 2, p. 129-136, 2007.

10. Davison, A. C.; Hinkley, D. V. Bootstrap methods and their application. New York: Cambridge University Press, 1997.

11. Duarte, M. D. L. R.; Albuquerque, F. C.; Sanhueza, R. M. V.; Verzignassi, J. R.; Kondo, N. Etiologia da podridão do coleto de Brachiara brizantha em pastagens da Amazônia. Fitopatologia Brasileira, v. 32, n. 3, p. 261-265, 2007.
12. Efron, B.; Tibshirani, R. An introduction to the bootstrap. New York: Chapman \& Hall, 1993. 456p.

13. Fenille, R. C.; Souza, N. L.; Kuramae, E. E. Characterization of Rhizoctonia solani associated with soybean in Brazil. European Journal of Plant Pathology, v. 108, p. 783-792, 2002.

14. González-Vera, A. D.; Bernardes-de-Assis, J.; Zala, M.; McDonald, B. A.; Correa-Victoria, F.; Graterol-Matute, E. J.; Ceresini, P. C. Divergence between sympatric rice- and maize-infecting populations of Rhizoctonia solani AG 1 IA from Latin America. Phytopathology, v. 100, n. 2, p. 172$182,2010$.

15. Hashiba, T.; Kobayashi, T. Rice diseases incited by Rhizoctonia species. In: Sneh, B.; Jabaji-Hare, S.; Neate, S.; Dijst, G. (Ed.). Rhizoctonia species: Taxonomy, molecular biology, ecology, pathology and disease control. Dordrecht: Kluwer Academic Publishers, 1996. p.331-340.

16. Houle, D. Comparing evolvability and variability of quantitative traits. Genetics, v. 130, n. 1, p. 195-204, 1992.

17. IBGE. Censo agropecuário 2006: Brasil, grandes regiões e unidades da federação. Rio de Janeiro: IBGE - Instituto Brasileiro de Geografia e Estatística, 2006. 777p.

18. Kelemu, S.; Miles, J. W.; Bonilla, X. P.; Badel, J. L. Sources of resistance in species of Brachiaria to foliar blight disease caused by Rhizoctonia solani. Tropical Grasslands, v. 29, p. 257-262, 1995.

19. Lee, F. N.; Rush, M. C. Rice sheath blight: a major rice disease. Plant Disease, v. 67, n. 7, p. 829-832, 1983.

20. Nechet, K. D. L.; Halfeld-Vieira, B. A. Reação de cultivares de feijão-caupi à mela (Rhizoctonia solani) em Roraima. Fitopatologia Brasileira, v. 32, p. 424-428, 2007.

21. Nechet, K. D. L.; Halfeld-Vieira, B. D. A.; Gianluppi, V.; Meyer, M. C. Reação de cultivares de soja à mela (Thanatephorus cucumeris) em campo em dois estádios de desenvolvimento das plantas. Summa Phytopathologica, v. 34, p. 277-279, 2008.

22. Padasht-Dehkaei, F.; Ceresini, P. C.; Zala, M.; Okhovvat, S. M.; Nikkhah, M. J.; Mcdonald, B. A. Population genetic evidence that basidiospores play an important role in the disease cycle of rice-infecting populations of Rhizoctonia solani AG-1 IA in Iran. Plant Pathology, v. 62, n. 1, p. 49-58, 2013.

23. Perdomo, R.; Hernández, A.; Gonzáles, A.; Pineda, J.; Alezones, J. Caracterización y evaluación de virulencia en aislamientos de Rhizoctonia solani Kühn, causante de la mancha bandeada en maíz. Interciencia, v. 32, n. 1, p. 48-55, 2007.

24. R Development Core Team. R: A language and environment for statistical computing. Vienna, Austria: R Foundation for Statistical Computing, 2008. 2673p.

25. Ramos Molina, L. M.; Chavarro Mesa, E.; Pereira, D. A. D. S.; Silva -Herrera, M. D. R.; Ceresini, P. C. Rhizoctonia solani AG-1 IA infects both rice and signalgrass in the Colombian Llanos. Pesquisa Agropecuária Tropical, v. 46, p. 65-71, 2016

26. Valle, L. D. C. S.; Valério, J. R.; Souza, O. C. D.; Fernandes, C. D.; Corrêa, E. S. Diagnóstico de morte de pastagens nas regiões leste e nordeste do estado de Mato Grosso. Campo Grande, MS: Embrapa Gado de Corte, 2000. 13 p. (Documentos). 